\title{
8
}
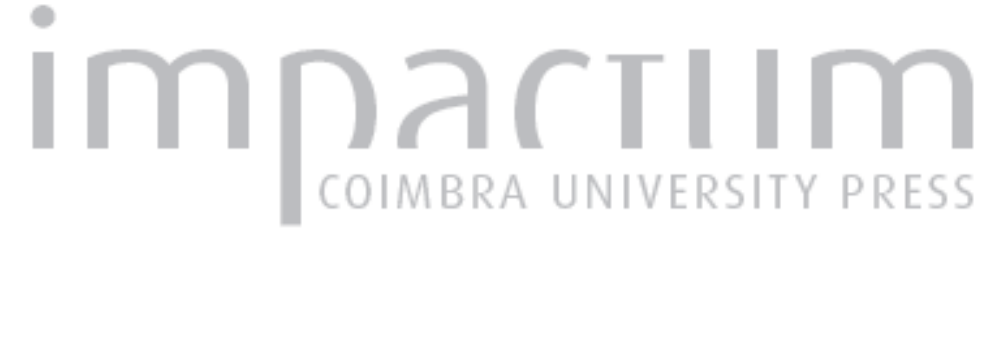

\section{Trabalhos recentes sobre a temática dos riscos (ditos) naturais}

Autor(es): Rebelo, Fernando

Publicado por: Associação Portuguesa de Riscos, Prevenção e Segurança

URL persistente:

URI:http://hdl.handle.net/10316.2/40116

DOI:

DOI:https://doi.org/10.14195/1647-7723_7_8

Accessed : $\quad$ 26-Apr-2023 15:35:28

A navegação consulta e descarregamento dos títulos inseridos nas Bibliotecas Digitais UC Digitalis, UC Pombalina e UC Impactum, pressupõem a aceitação plena e sem reservas dos Termos e Condições de Uso destas Bibliotecas Digitais, disponíveis em https://digitalis.uc.pt/pt-pt/termos.

Conforme exposto nos referidos Termos e Condições de Uso, o descarregamento de títulos de acesso restrito requer uma licença válida de autorização devendo o utilizador aceder ao(s) documento(s) a partir de um endereço de IP da instituição detentora da supramencionada licença.

Ao utilizador é apenas permitido o descarregamento para uso pessoal, pelo que o emprego do(s) título(s) descarregado(s) para outro fim, designadamente comercial, carece de autorização do respetivo autor ou editor da obra.

Na medida em que todas as obras da UC Digitalis se encontram protegidas pelo Código do Direito de Autor e Direitos Conexos e demais legislação aplicável, toda a cópia, parcial ou total, deste documento, nos casos em que é legalmente admitida, deverá conter ou fazer-se acompanhar por este aviso.

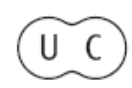


nos Pirenéus espanhóis, em 7 de Agosto de 1996, ou os terramotos de São Francisco (17 de Outubro de 1989), de Los Angeles (17 de Janeiro de 1994) e de Kobe (16de Janeiro de 1995) são referenciados com destaque.

Em nenhum dos casos apresentados, porém, há qualquer espécie de aprofundamento científico. Éo recordar da notícia, é a informação que se encontra. $\mathrm{E}$, obviamente, isso também nos interessa.

\section{REFERÊNCIAS BIBLIOGRÁFICAS}

FARRICA, José Guilherme Fernandes (1980) "O sismo de 1 de Janeiro de 1980 nos Açores". Finisterra, 15 (30), p. 247-261.
LOURENÇO, Luciano (1992) - “Avaliação do risco de incêndio nas matas e florestas de Portugal Continental", Finisterra, 27 (53-54), p. 115-140.

RAPOSO, A.G. B. (1998) - "Breve nota sobre a tragédia da Ribeira Quente(S. Miguel, Açores) ocorrida na madrugada de 31 de Outibro de 1997'. Territorium, 5, p. 73-74.

REBELO, Fernando (1997) - "Risco e crise nas inundações rápidas em espaço urbano. Alguns exemplos portugueses analisados a diferentes escalas". Territorium, 4, p. 29-47.

REBELO, F. e GANHO, N. (1998) - "As inundações do Outono de 1997 no Sul de Portugal". Territorium, 5 , p. 25-30.

\section{Trabalhos recentes sobre a temática dos riscos (ditos) naturais}

\section{Fernando Rebelo}

1. Enseigner les risques naturels. Pour une géographie physique revisitée (Paris, Anthropos/ GIP RECLUS, Economica, 1994, 227 p.) é um livro que, apesar dos seus seis anos de existência, se mantém profundamente actual. Coordenado por Bernard DUCRET, Professor de liceu em Annecy, teve como responsáveis pela sua preparação, além do coordenador, o seu colega Yves André, mas também os Professores Antoine BAIILY (Universidade de Genebra) e JeanPaul GUÉRIN (Instituto de Geografia Alpina da Universidade Joseph Fourier de Grenoble).

Uma Introdução de J.-P. GUÉRIN, intitulada "L'environnement-une question de représentations" abre um conjunto de doze capítulos que culminam com uma Conclusão assinada por A. BAILLY: "Pour un enseignement humain de la Géographie Physique". O mesmo Professor redigiu também os capítulos $8 \mathrm{e}$ 9, respectivamente, "L'éruption du Mont St. Helen's - prévention, information et représentations" e "Enseigner les risques naturels".

Todos os capítulos têm interesse para os estudiosos de riscos naturais. No entanto, merecem-nos destaque especial o 5, assinado por Bernard DEBARBIEUX (Instituto de Geografia Alpina) sobre "Le risque en montagne. Phénomène naturel ou phénomène social?" e o 6, assinado por Robert D'ERCOLE (Universidade das Antilhas e da Guiana) sobre "Mesurer le risque. Le volcan Cotopaxi et les populations proches".

2.ErnestZEBROWSKIJr.(1997), da Universidade Estadual da Pensilvânia, publicou na prestigiada Cambridge University Press, um livro sobre crises de origem natural devidamente apresentadas e explicadas cientificamente - Perils of a Restless Planet:
Scientific Perspectives on Natural Disasters.

Com 306 páginas, o livro está dividido em nove capítulos. O primeiro começa com 5 páginas dedicadas ao terramoto de Lisboa de 1755 - "Lisbon's Longest Day".

Muitos outros casos históricos anteriores ou posteriores são depois analisados; a variedade é grande tanto no respeitante ao tipo de crises, como aos exemplos dados. Destaquem-se, porém, as páginas do oitavo capítulo - "Deadly winds" - sobre ciclones tropicais e tornados, ou as do quinto - "Restless seas" - sobre "tsunamis".

No final, são apresentados apêndices importantes - "Notable Tsunamis", "Notable Earthquakes", "Notable East Coast Tropical Storms and Hurricanes" e "Killer Tornadoes", todos com as respectivas datas de ocorrência e locais afectados entre outras indicações. O índice que culmina o trabalho é bastante completo e permite encontrar rapidamente toda a informação desejada sobre riscos naturais e locais afectados pela sua manifestação.

3. Pierre MARTIN (1998), engenheiro especialista em geotecnia, publicou na EDISUD de Aix-en-Provence, um livro com um título tão curioso quanto provocatório - Ces Risques que l'on dit Naturels. $\mathrm{O}$ homem aparece envolvido por vezes na origem dos fenómenos que depois se dizem naturais, outras vezes no desenvolvimento das manifestações de crise como factor de vulnerabilidades.

Com 256 páginas, este trabalho apresenta além de um pequeno prefácio, quatro partes - "La nature des risques", "Des risques de toutes natures", "Que risque-t-on en France?" e "Pour aller plus loin". 
A terminar, a bibliografia "sumária" é quase simbólica, mas o índice "geográfico" é muito extenso e útil.

Embora bem escrito, portanto, de fácil leitura, o livro de Pierre Martin torna-se pesado por só ter texto - não há uma fotografia, não há uma figura. Os exemplos são muitos, o que não impede o autor de reflectir sobre riscos, de escrever sobre vulnerabilidades.

4. Yvette VEYRET, geógrafa e professora da Universidade de Paris VII, no seu mais recente livro, Géo-environnement (Paris, SEDES, 1999, 159 p.) também trata de riscos, especialmente nos capítulos 8, "Les nuisances urbaines", e 9, "Les risques urbains". No primeiro, preocupa-se com as poluições (do solo, do ar e das águas), mas também com os barulhos e os lixos, não deixando ainda de referir riscos de saúde, ligados ou não às diversas poluições. No segundo, trata dos riscos de inundaçãoe dos riscos tecnológicos, aí incluindo o risco de incêndio.

Outros capítulos têm ligações com a temática dos riscos e trazem, por vezes, exemplos franceses de grande interesse para o leitor. Particularmente importante é o anexo intitulado "Documents et méthodes" onde vários riscos são apresentados, quase sempre com ilustração de casos de manifestação de crises. Destaquem-se as páginas dedicadas aos riscos climáticos e aos riscos na montanha.

Como muitos dos seus leitores não são geógrafos, Y. VEYRET achou por bem terminar o seu livro com um "léxico", em que se explicam de modo simples alguns dos conceitos fundamentais referidos, e com uma bibliografia bastante variada.

5. Andrée DAGORNE (Mestre de Conferências de Geografia) e René DARS (Professor Emérito de Geologia), ambos da Universidade de Nice, Sophia-Antipolis, deram as mãos para fazer um pequeno livro da famosa colecção “Que-sais-je?” intitulado Les Risques Naturels. Saído em Dezembro de 1999, traz como sub-título La cindynique.

Trata-se, como é habitual nesta colecção, de um pequeno livro de 128 páginas onde se resumem as principais noções da Cindínica. Mesmo assim, tem um prefácio("Catastrophes, risques naturels, anthropiques et technologiques: la cyndinique") e uma introdução ("De la catastrophe au risque et à sa prise en compte. Les risques naturels dans le monde"), antes dos diversos capítulos agrupados em duas partes - "Les risques liés à la Géodynamique interne" e "Les risques liés à la Géodynamique externe". A conclusão geral intitulase "Vers un codéveloppement durable (ou soutenable)".

6. Assinado por Lesley Newson e traduzido por Paula Reis, foi editado pela Centralivros (Lisboa, 1999) o Atlas dos Piores Desastres Naturais no Mundo. Com fotografias mais ou menos dramáticas, muitas vezes verdadeiramente excepcionais, acompanhadas com frequência por mapas e esquemas explicativos, trata-se de um Atlas para o grande público. No capítulo intitulado "Vulcões e Sismos" temos a oportunidade de recordar catástrofes que foram notícia nos jornais e telejornais do mundo inteiro ou que conhecemos da bibliografia geográfica, geológica ou mesmo histórica. Entre as grandes crises de origem vulcânica são focadas, por exemplo, as de Heimaey (1973), Monte de Santa Helena (1980), Nevado del Ruiz (1983) e Monte Pinatubo (1991), mas também as de Monte Pelée (1902), Cracatoa (1883) e Vesúvio (79). Quanto às catástrofes de origem sísmica salientam-se as de Cidade do México (1985), Spitak (1988), Chimbote - Yungai (1979), Valdívia (1960), Tangshan (1976), Kobe (1995), não se esquecendo Lisboa (1755) e São Francisco (1906).

Segue-se o capítulo sobre "Tempestades Violentas", ilustrado desde logo com uma bela fotografia de um tornado acompanhado de relâmpagos. Texto e fotografias associam trovoadas a inundações rápidas, o que nem sempre é o caso. Vêm depois os tornados mais famosos mostrando-se várias fotografias que bem podem serconsideradas espectaculares. Os ciclones tropicais são exemplificados com o célebre "furacão Andrew" (1992), o "ciclone Tracy" (1974), o "furacão de Galveston" (1900) e o "ciclone 2B" (1991). $\mathrm{O}$ capítulo culmina com referência à chamada "Tempestade do século", que ocorreu na costa leste dos Estados Unidos em 1993.

"Extremos climáticos e extinções em massa" é o título do capítulo seguinte. E aí estão as grandes secas e os grandes incêndios como o da Austrália (1983) e o da Côte d'Azur (1985). As grandes inundações são exemplificadas com as do Rio Yangtzé (1991) e do Mississipi (1993), mas também com a do Mar do Norte (1953). Extinções durante os últimos tempos da história geológica fecham o capítulo.

O capítulo seguinte, "Competição pela vida" tem apenas duas páginas. Em contrapartida, "As pestes e as pragas" é longo e tanto se debruça sobre a peste negra como sobre a sida.

A parte dois deste livro intitula-se "Dicionário Geográfico" e tem todas as vantagens do livro que, além de algumas considerações no texto, mostra vários mapas com a localização dos factos que podem ocorrer como manifestação de crises.

7. Risques Naturels (Aix-en-Provence, Éditions du Comité des Travaux Historiques et Scientifiques, 1999, 159 p.) é um livro publicado sob a direcção de dois conhecidos geógrafos físicos franceses (Pierre GABERT e Jean VAUDOUR) e traz-nos trabalhos de vários autores. Christiane VILLAN-GANDOSSI ("Une analyse de l'approche globale des risques"), Jean-Michel DUTUIT e Pierre DUTUIT ("Perception 
et approche des risques majeurs anthropiques") e Jan BERTING ("L'interaction entre géosystèmes et systèmes sociaux") debruçam-se essencialmente sobre os conceitos; ficaram a seu cargo os três primeiros capítulos.

Os estudos de casos concretos de crises ocupam a maior parte do livro. Jean-Louis BALLAIS e Paul SÉGURA ("La catastrophe de Vaison-la-Romaine (22 septembre 1992): une inondation dans un géosystème anthropisé"), Jean-Louis BALLAIS, Thierry TORRES e Mirabelle FIANDINO ("L'inondation de la Touloubre (Bouches du Rhône) de septembre 1993 dans son contexte historique"), Abdelghani GARTET ("Violence des crues de l'oued Lebène et évolution des lits fluviaux (Prérif central, Maroc)"), Jean-Marc ANTOINE e Bertrand DESAILLY ("Nouvelles pratiques, nouveaux enjeux, nouveaux risques: l'exemple du Terrefort toulousain"), Sigolène PAILHÉS ("L'étang de tous les enjeux: une nouvelle approche des conséquences de l'aménagement hydroélectrique de la Durance sur l'étang de Berre"), Jean NICOD ("Phénomènes karstiques et mouvements de terrain récents dans le département du Var. Problèmes d'impact"), A. TOMAT e J.-P. DUPONT ("Les 'bétoires' en Haute Normandie")e Christine BOUSSET ("Gendarmes et forestiers en Roussillon: derrière les mots, le feu") apresentam um leque variado de casos, em geral, de forma precisa e cientificamente correcta, por vezes, com alguma preocupação teorizante, quase sempre, com o espírito crítico construtivo necessário para que o decisor, no futuro, tenha em atenção os riscos que até já se manifestaram como crises de maior ou menor dramatismo.

Não há propriamente uma Conclusão neste livro sobre Riscos Naturais nascido a partir de um Colóquio ("Congrès National des Sociétés Historiques et Scientifiques", Aix-en-Provence, 1995). Mas há uma Introdução de Pierre GABERT que apresenta, em curta síntese, muito do que se tem feito em França no respeitante aos riscos naturais.

8. Finalmente, dedicado ao povo terceirense e da autoria de Victor Hugo FORJAZ, Francisco ROCHA, José MEDEIROS, Luis MENESES e Cláudia SOUSA, veio a lume, em Ponta Delgada, no mês de Março do ano 2000, um pequeno livro intitulado Vulcão Oceânico da Serreta, que traz como subtítulo Notícias sobre o Vulcão Oceânico da Serreta, Ilha Terceira dos Açores. Apenas com 40 páginas, é um belo trabalho, muito bem ilustrado com esboços geológicos, mapas, esquemas, figuras diversas e, acima de tudo, fotografias por vezes impressionantes do que foi esta erupção desde a primeira vez que foi observada, em 18 de Dezembro de 1998, até aos inícios do ano 2000. Trata-se de uma edição do Observatório Vulcanológico e Geotérmico dos Açores, sendo o tex to da responsabilidade de Victor Hugo FORJAZ. 